\title{
The Situational Awareness \& The Port Pilotage Services
}

\author{
Authors: Serkan Kahraman and Yusuf Zorba \\ Reviewed by: Capt. Numan Cokgormusler, Ph.D. \\ Unlimited Master Mariner, Senior Harbour Pilot (Nemrut Bay and Port of Akcansa)
}

Keywords: Situational awareness, Maritime pilotage, Techno-nautical services, Port pilotage

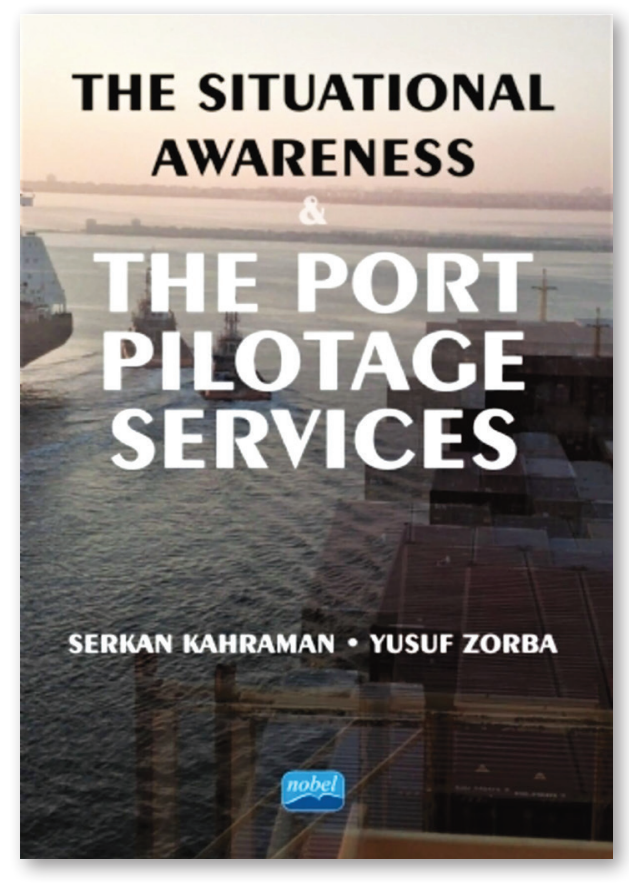

The main idea of the book includes valuable research on the effect of situational awareness and safe ship maneuvering in port pilotage services for the first time. In terms of scientific results, this study is both fascinating and remarkable. In the development of this research, a detailed, sufficient literature study was conducted. In addition, as evidenced by the results, this research elucidates studies that should be conducted in the future. Thus, I believe the book will be significant in the future.
The topic that the findings of this exceptional study raised for discussion is situational awareness in terms of scientific data, including its effect on life/property and environmental safety while providing port pilotage services, the difference it creates, the factors and components affecting it, and its relevance to safe maneuvering.

The two researchers who conducted this significant study and wrote this book have resumes and professional and academic careers that distinguish them as people with the highest level of qualification and skills required for conducting scientific research on this subject.

Mr. Yusuf Zorba, a graduate of İstanbul Technical University's Maritime Faculty with a bachelor degree in Maritime Transportation Engineering, has worked at various officer levels on ships of major chemical transportation companies in the Turkish maritime trade. Mr. Zorba is a valuable academician who works in maritime transportation engineering and management science fields, continuing his career as an Associate Professor at the Maritime Faculty of Dokuz Eylul University.

Mr. Serkan Kahraman earned a bachelor degree in Maritime Transportation Engineering from the Maritime Faculty of Istanbul Technical University and has worked in various positions on ships of major Turkish maritime trade companies. He has also worked as a pilot in the Turkish Straits, Port of Canakkale, Port of Izmir, and DP World Jebel Ali Port. Mr. Kahraman currently works as a pilot in Port of Tuzla and the Tuzla shipyards region. He is a valuable 
researcher who is also pursuing a doctoral degree owing to his interest in academia.

The first section of the book aims to provide general information about sea transportation and pilotage. Accordingly, maritime transportation was defined, and its global significance was revealed. Afterward, an attempt was made to explain port operations, ship services, and technonautical services. Pilotage services, as well as related international regulations, were mentioned as one of the services, with a focus on the laws and operation of pilotage services. Private and non-governmental organizations that work closely with ports to offer pilotage services in Turkey were also mentioned in the first chapter.

There was an attempt to disclose the importance of situational awareness for port pilotage services in the second section of the book, which emphasizes the relationship between pilotage services and safety. In the succeeding sections, the concept of situational awareness, its components, measurement methods, and measurement techniques are all discussed in detail. The places where situational awareness studies were conducted, as well as situational awareness studies on sea transportation, are evaluated at the end of the section.

The third section includes the simulation scenario created using the situation awareness global assessment technique, as well as the conducted experiments and findings for the above-mentioned objective. The conclusions made based on the findings are briefly stated.

The strength of this work, which deals with maritime transportation, a scientifically important subject, is that it is a reference study with its research model, sampling methods, and scientific methods clearly expressing the data on the subject, including its content and methodology. It also stands out as guiding research that highlights new studies that should be done in the future.

It is apparent that improving the international aspect of the field-specific, detailed research presented in this book would be beneficial, because, in my professional life, I have observed that situational awareness is related to education, service conditions, quality standards, and culture in the countries where service is received/provided. Owing to the aforementioned factors, evaluating the application as a single-country and single-nationality research limits the data, particularly during the procurement of the subject service. Thus, to determine the accuracy of evaluations, they must be developed and implemented in the future. I believe that the research should be considered a new and developing area for researchers in this field, and its positive and negative effects on the situational awareness of captains and/or pilots should be investigated in future studies. In addition, in the discussion section of the book, the general assumption that pilots "have been ship captains before" is considered, and the development of experience is conveyed. Some countries do not have such a requirement for pilots. Therefore, another point to explore is if the time spent as a captain and the experience affect the situational awareness of the pilotage service or if there is a correlation between the two. Notably, the fact that it causes us to consider all these issues is a compelling reason to examine and evaluate the book.

Viewing the book from a general perspective, it is apparent that no previous study or research of this scope and type has been conducted on a sectoral basis. Thus, I believe that the book will be a valuable resource for professionals and decision-makers working in the maritime industry, particularly researchers/authors. In addition, I acknowledge all who contributed to the emergence of such a significant work and its application to the maritime industry. I hope that the maritime industry will benefit from this work, which I believe will elucidate and guide similar and more specific studies in the future.

\section{Dr. Capt. Numan Cokgormusler}

Dr. Capt. Numan Cokgormusler graduated from the Maritime Faculty of Istanbul Technical University with a degree in Maritime Transportation Engineering in 1992. From 1992 to 1996, he worked on ships at various officer levels before becoming a lecturer at Dokuz Eylul University's Maritime Business and Management School. After completing his doctoral studies in Maritime Economics at İstanbul University, he worked as a visiting lecturer at Maine Maritime Academy in the USA. In 2000, he returned to sea service, and in 2003, he began a maritime pilotage career with UZMAR Pilotage Co. in the Nemrut Bay area. Since 2015, Dr. Capt. Numan Cokgormusler has been serving as a Master in the Turkish merchant fleet. 